\title{
Is There a Relationship Between Fatigue Perception and the Serum Levels of Thyrotropin and Free Thyroxine in Euthyroid Subjects?
}

\author{
Annenienke C. van de Ven, ${ }^{1}$ Romana T. Netea-Maier, ${ }^{1}$ Femmie de Vegt, ${ }^{2} \mathrm{H}$. Alec Ross, ${ }^{3}$ \\ Fred C.G.J. Sweep, ${ }^{3}$ Lambertus A. Kiemeney, ${ }^{2,4}$ Ad R. Hermus, ${ }^{1}$ and Martin den Heijer ${ }^{1,2}$
}

Background: Thyrotoxicosis and hypothyroidism are associated with fatigue. Here we studied euthyroid subjects to determine if there was a relationship between serum thyrotropin (TSH), free thyroxine $\left(\mathrm{FT}_{4}\right)$ and thyroperoxidase antibodies and fatigue.

Methods: A total of 5897 participants of the Nijmegen Biomedical Study received a questionnaire and serum TSH (normal range 0.4-4.0 mIU/L) and $\mathrm{FT}_{4}$ (normal range 8-22 pmol/L) were measured. Fatigue was evaluated by the RAND-36 and the shortened fatigue questionnaire (SFQ).

Results: Euthyroid subjects with a serum TSH level of 0.4-1.0 mIU/L had a lower RAND-36 vitality score (65.2 vs. 66.8; regression coefficient (RC) -1.6 [95\% confidence interval (CI) -2.6 to -0.5$] ; p=0.005$ ) and a higher SFQ score (11.7 vs. 11.0; RC 0.6 [CI 0.2-1.0]; $p=0.004$ ) than those with a TSH of 1.0-2.0 mIU/L. Those with a serum $\mathrm{FT}_{4}$ of $18.5-22 \mathrm{pmol} / \mathrm{L}$ reported fatigue more often (52.5\% vs. 33.3\%; relative risk (RR) 1.4 [CI 1.0-1.9]; $p=0.03$ ), had a lower RAND-36 vitality score (61.7 vs. 66.6; RC -4.4 [CI -8.1 to -0.6$] ; p=0.02$ ) and a higher SFQ score (13.2 vs. 11.0; RC 1.9 [CI 0.4-3.3]; $p=0.01$ ) than subjects with a $\mathrm{FT}_{4}$ level of 11.5-15 pmol/L. In comparison to euthyroid subjects without known thyroid disease, euthyroid subjects with previously known thyroid disease reported fatigue more often ( $52.3 \%$ vs. $34.0 \%$; RR 1.3 [CI 1.0-1.5]; $p=0.025)$, had a lower RAND-36 vitality score (61.4 vs. 66.3; RC -2.9 [CI -5.3 to -0.6$] ; p=0.015)$ and a higher SFQ score (13.7 vs. 11.1; RC 1.4 [CI 0.5-2.3]; $p=0.002)$.

Conclusion: In euthyroid individuals without a history of thyroid disease, there is a modest relationship between thyroid function and fatigue with subjects having an apparently higher production of $\mathrm{T}_{4}$ experiencing more fatigue. Subjects with a history of thyroid disease, but with normal TSH and $\mathrm{FT}_{4}$ concentrations, experience more fatigue than the general population. The reasons for this are unclear, but subtle abnormalities in the dynamics of thyroid hormone secretion should be considered.

\section{Introduction}

$\mathbf{T}$ HYROID DYSFUNCTION IS common in the general population (1-4). Fatigue is a frequently reported symptom of patients with both hyper- and hypothyroidism (5-9). Fatigue is also one of the most relevant symptoms for patients with thyroid dysfunction impairing their quality of life $(9,10)$. As for mild degrees of thyroid dysfunction, Canaris et al. reported more symptoms, including feeling more tired, in subclinically hypothyroid subjects in comparison to euthyroid subjects in a large population-based study (2). In contrast, Grabe et al. found no increase of fatigue in subjects with subclinical and overt hypo- or hyperthyroidism in a population-based study (11).
In the absence of suitable methods for measuring thyroid hormone and thyrotropin (TSH) production rates in groups of patients, by generally accepted definition, subjects with serum $\mathrm{TSH}$ and free thyroxine $\left(\mathrm{FT}_{4}\right)$ concentrations within the normal range are considered to be euthyroid. Previous studies have shown an association between variations in serum TSH and $\mathrm{FT}_{4}$ concentrations within the normal range and cardiovascular risk, blood pressure, body mass index (BMI), incidence of atrial fibrillation, and serum cholesterol (12-17). These results raise the question of whether there is also an association between fatigue and serum TSH and $\mathrm{FT}_{4}$ within the normal range. Recently, an association between the level of thyroperoxidase antibodies (TPOAbs) and fatigue has been described in euthyroid women with a goiter (18). This raises

Departments of ${ }^{1}$ Endocrinology, ${ }^{2}$ Epidemiology, Biostatistics, \& HTA, ${ }^{3}$ Laboratory Medicine, and ${ }^{4}$ Urology, Radboud University Nijmegen Medical Center, Nijmegen, The Netherlands. 
the question whether TPOAb levels are associated with fatigue in the general population.

The present study had several goals. The first was to investigate whether unsuspected thyroid dysfunction (i.e., overt or subclinical thyrotoxicosis or overt or subclinical hypothyroidism) as uncovered in a population, was associated with the prevalence and severity of fatigue. The second was to investigate whether, in subjects whose serum $\mathrm{TSH}$ and $\mathrm{FT}_{4}$ are in the normal range, there is a relationship between the levels of serum TSH or serum $\mathrm{FT}_{4}$ and the prevalence and severity of fatigue. The last was to determine in apparently euthyroid subjects (i.e., normal TSH and $\mathrm{FT}_{4}$ ) whether there is an association between the presence of TPOAbs and fatigue.

\section{Methods}

\section{Study participants}

The subjects of this study were participants of the Nijmegen Biomedical Study, a large, population-based survey performed in Nijmegen, a town in the eastern part of The Netherlands. Details of this study have been described previously (4). Approval to conduct the study was obtained from the Institutional Review Board. A total of 22,451 age- and sexstratified randomly selected adults received a questionnaire on lifestyle, medical history, and symptoms. Of each agegroup (range 5 years), 750 men and 750 women were invited to participate. We excluded pregnant women and subjects using medication interfering with thyroid function, such as lithium, amiodarone, kelp, oral glucocorticosteroids, and/or dopamine agonists because of the possible effect of these conditions and medications on thyroid function. To investigate the population without known thyroid disease, we excluded the subjects with previously known thyroid disease, subjects using thyromimetic and/or thyrostatic drugs, and subjects with a history of thyroid surgery and/or ${ }^{131} \mathrm{I}$ treatment.

\section{Laboratory methods}

Serum TSH was measured by an immunoluminometric assay on a random access analyzer (Architect; Abbott Diagnostics Division). The reference interval used in our laboratory is $0.4-4.0 \mathrm{mIU} / \mathrm{L}$. Serum $\mathrm{FT}_{4}$ was measured with a luminescence enzyme immunoassay on a random-access assay system (Vitros ECI; Ortho Clinical Diagnostics). Our laboratory reference interval is $8.0-22.0 \mathrm{pmol} / \mathrm{L}$. Antibodies against TPO (TPOAbs) were measured with a fluorescence immunoenzymometric assay for the quantitative measurement of the immunoglobulin G class of anti-TPOAbs (AxSYM Anti-TPO; Abbott Diagnostics Division). The reference interval was defined as $<12 \mathrm{kIU} / \mathrm{L}$ (data provided by manufacturer). More details about these measurements are described elsewhere (4). Thyroid function was classified as overt thyrotoxicosis if TSH was $<0.4 \mathrm{mIU} / \mathrm{L}$ and $\mathrm{FT}_{4}$ was $>22 \mathrm{pmol} / \mathrm{L}$ and it was classified as subclinical thyrotoxicosis if TSH was $<0.4 \mathrm{mIU} / \mathrm{L}$ and $\mathrm{FT}_{4}$ was $\geq 8$ and $\leq 22 \mathrm{pmol} / \mathrm{L}$. Thyroid function was classified as overt hypothyroidism if TSH was $>4.0 \mathrm{mIU} / \mathrm{L}$ and $\mathrm{FT}_{4}$ was $<8 \mathrm{pmol} / \mathrm{L}$ and as subclinical hypothyroidism if TSH was $>4.0 \mathrm{mIU} / \mathrm{L}$ and $\mathrm{FT}_{4}$ was $\geq 8$ and $\leq 22 \mathrm{pmol} / \mathrm{L}$. When both TSH and $\mathrm{FT}_{4}$ were within normal range, thyroid function was classified as euthyroidism. When either TSH or $\mathrm{FT}_{4}$ was not within the normal range, thyroid function was classified as thyroid dysfunction. Subjects with overt thyrotoxicosis, subclinical thyrotoxicosis, overt hypothyroidism, or subclinical hypothyroidism were considered to have thyroid dysfunction.

\section{Questionnaire}

The questionnaire contained questions about gender, age, weight, height, lifestyle, medical history, and the use of medication. The presence of the symptom fatigue was evaluated by the question: "Do you feel tired?" Data on the presence of the symptom fatigue were missing in 119 subjects. The subscale vitality (energy and fatigue) of the RAND-36 Item Health Survey 1.0 was used to determine the intensity of fatigue (19).The items of the subscale vitality are identical to the MOS SF-36 (20). The subscale vitality of the RAND-36, translated in Dutch, has a good internal reliability (Cronbachs $\alpha: 0.82)(21,22)$. It consists of four questions: "How much of the time during the past 4 weeks - did you feel full of life? - did you have a lot of energy? — did you feel worn out?- did you feel tired?" The participants choose the best option of the six possible answers given for each question: "all of the time," "most of the time," "a good bit of the time," "some of the time," "a little of the time," or "none of the time." All items were scored on a 0-100 range and recoded so that a high score defined a more favorable health state. The average score of the four questions was calculated. When one or two items were missing, the average score of the other two or three questions was used. If three or four items were missing, the total score was defined as missing and not used for the analyses. The score of the subscale vitality of the RAND-36 was missing in 178 subjects. A higher score is associated with having more energy and less fatigue, with a maximum score of 100 . The average score of the subscale vitality of the RAND-36 in a Dutch cohort consisting of 1063 subjects, aged 18-89 years, was $67.4 \pm 19.9$ (22). In this cohort, young adults (19-24 years old) scored on average 69.2 points, whereas elderly (75-85 years old) scored on average 60.1 points.

In addition, the shortened fatigue questionnaire (SFQ) was also used to determine the intensity of the fatigue $(23,24)$. The SFQ is a short and easy to use instrument to determine the intensity of fatigue. The SFQ has a good internal reliability (Cronbach $\alpha: 0.88$ ) and discriminating validity. It consists of four statements: "I feel tired," "I tire easily," "I feel fit," and "I feel physically exhausted." The participants rated the statements for the degree of being true at a 7-point scale and for each answer, points were granted. A higher score is associated with being more tired, with a maximum score of 28 points. Healthy adults, without any stressful conditions, score on average $5-8$ points, whereas, for example, patients with cancer score on average 13-21 points (23). The SFQ score was missing in 497 subjects.

\section{Statistical analysis}

The BMI was calculated by dividing the body weight $(\mathrm{kg})$ by the square of the height (m). Relative risks (RRs) along with the $95 \%$ confidence intervals (CIs) were estimated using loglinear regression analyses, with fatigue as the dependent variable and thyroid function class and TSH and $\mathrm{FT}_{4}$ subclasses within the normal range as the independent variables (25-27). Also the presence of TPOAbs (defined as $>12 \mathrm{kIU} / \mathrm{mL}$ according to the reference interval provided 
by the manufacturer) and the presence of known thyroid disease were used as independent variables in the loglinear analysis.

To compare the score of the vitality subscale of the RAND36 and the SFQ score of each thyroid function class, we used linear regression analyses with the fatigue score as the dependent variable and thyroid function class as the independent variable. Within the normal range of thyroid function, we used subclasses of TSH and $\mathrm{FT}_{4}$ for linear regression analyses with the score of the subscale vitality of the RAND-36 or the SFQ score as the dependent variable and the TSH subclasses and $\mathrm{FT}_{4}$ subclasses as the independent variables. TPOAb levels were also used as the independent variables for linear regression analyses with the score of the subscale vitality of the RAND-36 or the SFQ score as the dependent variable.

All regression analyses were adjusted for gender, age, BMI, and smoking status to eliminate possible confounders. In addition, we adjusted for a medical history of chronic obstructive pulmonary disease (COPD)/asthma, rheumatoid disease, cardiovascular disease (CVD), cancer, diabetes mellitus, kidney disease, liver disease, and C-reactive protein (CRP) to rule out the possible confounding effect of nonthyroidal illness. We analyzed the data with STATA version 11.0 (StataCorp, Texas).

\section{Results}

A total of 9350 subjects receiving a questionnaire responded (response rate: $42 \%$ ). Of the responders, 6434 subjects $(69 \%)$ gave permission for blood withdrawal. The subjects who gave permission for blood withdrawal differed only slightly from the subjects who did not donate blood samples: the mean age was 56 vs. 53 years, the percentage of women was $54 \%$ vs. $50 \%$, the prevalence of fatigue was $36 \%$ vs. $37 \%$, the mean RAND-36 vitality score was 65.7 vs. 63.9 , and the SFQ score was 11.4 vs. 12.2, respectively. We excluded 47 pregnant women and 162 subjects using medications interfering with thyroid function. In addition, we excluded 328 subjects because of previously-known thyroid disease.

The characteristics of the remaining 5897 subjects are shown in Table 1 . Their age ranged from 18 to 98 years. Female gender, a higher age, a higher BMI, and a medical history of CVD, cancer, diabetes, rheumatoid arthritis, asthma/ COPD, renal disease, liver disease, and a high CRP were all associated with a higher prevalence of fatigue.

Table 2 shows the prevalence of self-reported fatigue, the RAND-36 vitality subscale score, and the SFQ score according to the thyroid function class. Subjects with thyroid dysfunction reported fatigue more frequently $(39.6 \%)$ than euthyroid subjects $(34.0 \%)$, but this difference was not statistically significant. The RR was 1.2 [CI 0.996-1.4], $p=0.055$. After adjustment for possible confounders, the RR was 1.1 [CI 0.9-1.3], $p=0.34$. There was no statistically significant difference in the RAND-36 score or the SFQ score between euthyroid subjects and subjects with thyroid dysfunction, neither before nor after adjustment for possible confounders.

The prevalence of fatigue, the score of the subscale vitality of the RAND-36 and the SFQ score by TSH and $\mathrm{FT}_{4}$ subclasses within the normal range (i.e., in euthyroid subjects) are shown in Table 3.Within the normal range of TSH, subjects with a TSH level of $0.4-1.0 \mathrm{mIU} / \mathrm{L}$ had a lower RAND-36 vitality score (65.2 vs. 66.8 ; mean difference -1.6 [CI -2.6 to -0.5$]$; $p=0.005)$ and a higher SFQ score (11.7 vs. 11.0 ; mean difference 0.6 [CI $0.2-1.0] ; p=0.004$ ) than those with a serum TSH of 1.0-2.0 $\mathrm{mIU} / \mathrm{L}$, after adjustment for possible confounders. Subjects with a serum $\mathrm{FT}_{4}$ level of $18.5-22 \mathrm{pmol} / \mathrm{L}$ reported fatigue more often (52.5\% vs. $33.3 \%$; RR 1.4 [CI 1.0-1.9]; $p=0.03$ ), had a lower RAND-36 vitality score (61.7 vs. 66.6; mean difference $-4.4[\mathrm{CI}-8.1$ to -0.6$] ; p=0.02$ ) and a higher

Table 1. Characteristics of the Population

\begin{tabular}{|c|c|c|c|}
\hline Characteristic & $\begin{array}{c}\text { Total } \\
\mathrm{n}=5897\end{array}$ & $\begin{array}{c}\text { Female } \\
\mathrm{n}=3101\end{array}$ & $\begin{array}{c}\text { Male } \\
\mathrm{n}=2796\end{array}$ \\
\hline Age (years) & $55.6 \pm 17.9$ & $53.1 \pm 18.1$ & $58.5 \pm 17.2$ \\
\hline BMI $\left(\mathrm{kg} / \mathrm{m}^{2}\right)$ & $25.2 \pm 4.1$ & $24.8 \pm 4.5$ & $25.6 \pm 3.6$ \\
\hline Smoking $[n(\%)]$ & $1327(22.5 \%)$ & $652(21.0 \%)$ & $675(24.1 \%)$ \\
\hline \multicolumn{4}{|l|}{ Medical history of } \\
\hline COPD/asthma $[n(\%)]$ & $725(12.3 \%)$ & $375(12.1 \%)$ & $350(12.5 \%)$ \\
\hline $\operatorname{CVD}[n(\%)]$ & $586(9.9 \%)$ & $161(5.2 \%)$ & $425(15.2 \%)$ \\
\hline Rheumatic disease $[n(\%)]$ & $502(8.5 \%)$ & $329(10.6 \%)$ & $173(6.2 \%)$ \\
\hline Cancer $[n(\%)]$ & $453(7.7 \%)$ & $229(7.4 \%)$ & $224(8.0 \%)$ \\
\hline Diabetes mellitus [ $n(\%)]$ & $321(5.4 \%)$ & $145(4.7 \%)$ & $176(6.3 \%)$ \\
\hline Kidney disease $[n(\%)]$ & $173(2.9 \%)$ & $87(2.8 \%)$ & $86(3.1 \%)$ \\
\hline Liver disease $[n(\%)]$ & $138(2.3 \%)$ & $79(2.5 \%)$ & $59(2.1 \%)$ \\
\hline $\mathrm{CRP}>10 \mathrm{mg} / \mathrm{L}[n(\%)]$ & $544(9.2 \%)$ & $290(9.4 \%)$ & $254(9.1 \%)$ \\
\hline Fatigue $[n(\%)]$ & $1989(34.4 \%)$ & $1195(39.5 \%)$ & $794(28.9 \%)$ \\
\hline RAND-36 score & $66.2 \pm 17.4$ & $64.1 \pm 17.3$ & $68.6 \pm 17.3$ \\
\hline SFQ score & $11.2 \pm 6.4$ & $12.0 \pm 6.6$ & $10.3 \pm 6.1$ \\
\hline TSH $(\mathrm{mIU} / \mathrm{L})$ & $1.4(0.9-2.0)$ & $1.4(0.9-2.0)$ & $1.4(0.9-1.9)$ \\
\hline $\mathrm{FT}_{4}(\mathrm{pmol} / \mathrm{L})$ & $13.3(12-14.6)$ & $13.3(12-14.6)$ & $13.3(12-14.7)$ \\
\hline TPOAbs positive $[n(\%)]$ & $747(12.7 \%)$ & $520(16.8 \%)$ & $227(8.1 \%)$ \\
\hline Euthyroid $[n(\%)]$ & $5439(92.2 \%)$ & $2823(91.0 \%)$ & $2616(93.6 \%)$ \\
\hline
\end{tabular}

Data are reported as number (percent), mean \pm standard deviation, or median (IQR).

$\mathrm{BMI}$, body mass index; COPD, chronic obstructive pulmonary disease; CVD, cardiovascular disease; $\mathrm{CRP}, \mathrm{C}$-reactive protein; $\mathrm{FT}_{4}$, $\mathrm{free}$ thyroxine; IQR, interquartile range; SFQ, shortened fatigue questionnaire; TSH, thyrotropin; TPOAbs, thyroperoxidase antibodies. 
Table 2. Self-Reported Fatigue and Scores of the RAND-36 Vitality Subscale and SFQ by Thyroid Function Class, in Subjects Free of Known Thyroid Disorder $(N=5897)$

\begin{tabular}{|c|c|c|c|c|c|c|c|}
\hline \multirow[b]{2}{*}{ Subjects } & \multirow[b]{2}{*}{$\mathrm{n}$} & \multicolumn{2}{|c|}{ Self-reported fatigue } & \multicolumn{2}{|c|}{ RAND-36 vitality } & \multicolumn{2}{|r|}{$S F Q$} \\
\hline & & $\%$ & $R R[C I]$ & Score & $\mathrm{RC}[\mathrm{CI}]$ & Score & $\mathrm{RC}[\mathrm{CI}]$ \\
\hline Euthyroidism & 5439 & 34.0 & Reference & 66.3 & Reference & 11.1 & Reference \\
\hline Thyroid dysfunction $^{\mathrm{a}}$ & 458 & 39.6 & $1.1[0.9-1.3]$ & 65.4 & $-0.3[-1.9-1.4]$ & 11.6 & $0.1[-0.5-0.7]$ \\
\hline Overt thyrotoxicosis & 9 & 55.6 & $1.6[0.7-3.9]$ & 63.9 & $-1.9[-12.8-9.0]$ & 13.8 & $2.4[-1.5-6.3]$ \\
\hline Subclinical thyrotoxicosis & 196 & 37.0 & $1.0[0.8-1.3]$ & 65.0 & $-0.8[-3.3-1.7]$ & 11.9 & $0.4[-0.5-1.3]$ \\
\hline Subclinical hypothyroidism & 216 & 42.8 & 1.1 [0.9-1.4] & 66.0 & $0.3[-2.1-2.7]$ & 11.2 & $-0.3[-1.2-0.6]$ \\
\hline Overt hypothyroidism & 22 & 28.6 & $0.8[0.4-1.8\}$ & 67.6 & $1.7[-5.5-8.8]$ & 11.5 & $0.2[-2.5-2.9]$ \\
\hline
\end{tabular}

The relative risks (RRs) and regression coefficients (RCs) [with 95\% confidence interval (CI)] were adjusted for gender, age, BMI, smoking status, and comorbidity.

${ }^{\mathrm{a}}$ Of the subjects with thyroid dysfunction, seven subjects had a serum TSH $>0.4 \mathrm{mIU} / \mathrm{L}$ and $\mathrm{FT}_{4}>22 \mathrm{pmol} / \mathrm{L}$, and eight subjects had a serum TSH $<4.0 \mathrm{mIU} / \mathrm{L}$ and $\mathrm{FT}_{4}<8 \mathrm{pmol} / \mathrm{L}$.

SFQ score (13.2 vs. 11.0; mean difference 1.9 [CI 0.4-3.3]; $p=0.01$ ) than subjects with a serum $\mathrm{FT}_{4}$ level of $11.5-15 \mathrm{pmol} / \mathrm{L}$. Of the 1493 subjects with a TSH level between 0.4 and $1.0 \mathrm{mIU} / \mathrm{L}, 2.7 \%$ of the subjects (40 subjects) had a $\mathrm{FT}_{4}$ level between 18.5 and $22 \mathrm{pmol} / \mathrm{L}$. These 40 subjects reported fatigue more often (58\% vs. 36\%; RR 1.6 [CI 1.2-2.2]; $p=0.001$ ), had a (not statistically significant) lower RAND-36 vitality subscale score (62.2 vs. 65.2; regression coefficient (RC) -3.2 [CI -9.02.5]; $p=0.27$ ) and a higher SFQ score (13.6 vs 11.6; RC 2.2 [CI $0.1-4.3$ ]; $p=0.04$ ) than subjects with a TSH level between 0.4 and $1.0 \mathrm{mIU} / \mathrm{L}$ and $\mathrm{FT}_{4}$ level between 8 and $18.5 \mathrm{pmol} / \mathrm{L}$. Of the 91 subjects with a $\mathrm{FT}_{4}$ level between 18.5 and $22 \mathrm{pmol} /$ L, $44.0 \%$ of the subjects (40 subjects) had a TSH level between 0.4 and $1.0 \mathrm{mIU} / \mathrm{L}$. These 40 subjects did not differ from the 51 subjects with a TSH level between 1.0 and $4.0 \mathrm{mIU} / \mathrm{L}$ in self-reported fatigue, the RAND-36 vitality subscale score, and the SFQ score (self-reported fatigue $58 \%$ vs. $48 \%$; RR 1.4 [CI 0.9-2.1]; $p=0.11$; RAND-36 vitality subscale score 62.2 vs. 61.3; RC -0.2 [CI -7.6-7.3]; $p=0.97$; SFQ score 13.6 vs. 12.8; RC 1.5 [CI $-1.3-4.3] ; p=0.30)$. There were no differences in gender, BMI, smoking status, or comorbidity between the subclasses of TSH and $\mathrm{FT}_{4}$. However, subjects with a TSH level of $0.4-1.0 \mathrm{mIU} / \mathrm{L}$ and subjects with a serum $\mathrm{FT}_{4}$ level of 18.5-22 pmol/L were older (mean age 57.9 and 67.2 years, respectively) than the reference group (mean age 54.6 and 54.1 years, respectively). Subanalyses using different age groups gave similar results regarding the association between the subclasses of TSH and $\mathrm{FT}_{4}$ levels within the normal range and fatigue (self-reported fatigue, RAND-36 vitality subscale score, and SFQ score) (data not shown).

There was no association between the prevalence of selfreported fatigue, the RAND-36 vitality subscale score or the SFQ score and the presence of TPOAbs, neither in euthyroid subjects nor in subjects with thyroid dysfunction (Table 4). Subdividing the subjects with TPOAbs according to the level of TPOAbs did not change these results (data not shown).

When comparing the study population with the subjects excluded because of previously known thyroid disorder, subjects with a known thyroid disorder reported fatigue more often ( $50 \%$ vs. $34.4 \%$, RR 1.2 [CI 1.0-1.4]; $p=0.03)$, had a lower RAND-36 vitality score (61.8 vs. 66.2 ; mean difference -2.6 [CI -4.5 to -0.6$] ; p=0.01$ ) and a higher SFQ score (13.5 vs. 11.2; mean difference 1.3 [CI 0.6-2.1]; $p<0.001$ ) than subjects without known thyroid disorder (Table 5). Even in subjects who had serum TSH and $\mathrm{FT}_{4}$ concentrations in the normal range, those with previously known thyroid disease reported fatigue more often (52.3\% vs. $34.0 \%$; RR 1.3 [CI 1.0-1.5]; $p=0.025)$, and had a lower RAND-36 vitality score (61.4 vs. 66.3; mean difference -2.9 [CI -5.3 to -0.6$] ; p=0.015)$ and a higher SFQ score $(13.7$ vs. 11.1; mean difference 1.4 [CI 0.5-2.3]; $p=0.002)$. The median TSH of euthyroid subjects without previously known thyroid disease was $1.4 \mathrm{mIU} / \mathrm{L}$ (interquartile range [IQR] 1.0-1.9). The

Table 3. Self-Reported Fatigue and Scores of the RAND-36 Vitality Subscale and SFQ in Euthyroid Subjects, Free of Known Thyroid Disorder, by TSH and FT 4 Within the Normal Range $(N=5439)$

\begin{tabular}{|c|c|c|c|c|c|c|c|c|}
\hline \multirow[b]{2}{*}{ Subjects } & & \multirow[b]{2}{*}{$\mathrm{n}$} & \multicolumn{2}{|c|}{ Self-reported fatigue } & \multicolumn{2}{|c|}{ RAND-36 vitality } & \multicolumn{2}{|r|}{$S F Q$} \\
\hline & & & $\%$ & $R R[C I]$ & Score & $\mathrm{RC}[\mathrm{CI}]$ & Score & $R C[C I]$ \\
\hline TSH & $0.4-1.0 \mathrm{mIU} / \mathrm{L}$ & 1493 & 36.2 & $1.1[0.97-1.2]$ & 65.2 & $-1.6[-2.6 \text { to }-0.5]^{\mathrm{a}}$ & 11.7 & $0.6[0.2-1.0]^{\mathrm{a}}$ \\
\hline TSH & $1.0-2.0 \mathrm{mIU} / \mathrm{L}$ & 2754 & 33.3 & Reference & 66.8 & Reference & 11.0 & Reference \\
\hline TSH & $2.0-3.0 \mathrm{mIU} / \mathrm{L}$ & 918 & 31.7 & $1.0[0.8-1.1]$ & 66.9 & $0.4[-0.9-1.7]$ & 10.7 & $-0.4[-0.9-0.1]$ \\
\hline TSH & $3.0-4.0 \mathrm{mIU} / \mathrm{L}$ & 274 & 36.3 & $1.1[0.9-1.4]$ & 65.7 & $-0.8[-2.9-1.3]$ & 11.1 & $0.0[-0.8-0.8]$ \\
\hline $\mathrm{FT}_{4}$ & $8.0-11.5 \mathrm{pmol} / \mathrm{L}$ & 808 & 33.4 & $1.0[0.9-1.2]$ & 66.4 & $-0.1[-1.5-1.2]$ & 11.1 & $0.0[-0.5-0.5]$ \\
\hline $\mathrm{FT}_{4}$ & 11.5-15 pmol/L & 3517 & 33.3 & Reference & 66.6 & Reference & 11.0 & Reference \\
\hline $\mathrm{FT}_{4}$ & $15-18.5 \mathrm{pmol} / \mathrm{L}$ & 1023 & 35.3 & $1.0[0.9-1.1]$ & 65.7 & $-0.3[-1.5-0.9]$ & 11.5 & $0.2[-0.3-0.6]$ \\
\hline $\mathrm{FT}_{4}$ & $18.5-22 \mathrm{pmol} / \mathrm{L}$ & 91 & 52.2 & $1.4[1.0-1.9]^{\mathrm{a}}$ & 61.7 & $-4.4[-8.1 \text { to }-0.6]^{a}$ & 13.2 & $1.9[0.4-3.3]^{\mathrm{a}}$ \\
\hline
\end{tabular}

The RRs and RCs [with CI] were adjusted for gender, age, BMI, smoking status, and comorbidity.

${ }^{\mathrm{a}} p<0.05$. 
Table 4. Self-Reported Fatigue and Scores of the RAND-36 Vitality Subscale and SFQ вy TPOAв Subclasses in Subjects Free of Known Thyroid Disorder $(N=5897)$

\begin{tabular}{|c|c|c|c|c|c|c|c|}
\hline \multirow[b]{2}{*}{ Subjects } & \multirow[b]{2}{*}{$\mathrm{n}$} & \multicolumn{2}{|c|}{ Self-reported fatigue } & \multicolumn{2}{|c|}{ RAND-36 vitality } & \multicolumn{2}{|r|}{$S F Q$} \\
\hline & & $\%$ & $R R[C I]$ & Score & $\mathrm{RC}[\mathrm{CI}]$ & Score & $\mathrm{RC}[\mathrm{CI}]$ \\
\hline \multicolumn{8}{|c|}{ Total population } \\
\hline TPOAbs - & 5150 & 34.3 & Reference & 66.3 & Reference & 11.2 & Reference \\
\hline TPOAbs + & 747 & 35.3 & $1.0[0.8-1.1]$ & 66.0 & $0.5[-0.9-1.8]$ & 11.3 & $-0.1[-0.6-0.4]$ \\
\hline \multicolumn{8}{|c|}{ Euthyroid subjects } \\
\hline TPOAbs - & 4870 & 33.9 & Reference & 66.3 & Reference & 11.1 & Reference \\
\hline TPOAbs + & 569 & 34.6 & $1.0[0.8-1.1]$ & 66.3 & $0.7[-0.9-2.2]$ & 11.4 & $0.1[-0.5-0.7]$ \\
\hline \multicolumn{8}{|c|}{ Subjects with thyroid dysfunction } \\
\hline TPOAbs - & 280 & 48.9 & Reference & 65.6 & Reference & 12.0 & Reference \\
\hline TPOAbs + & 178 & 42.1 & $0.8[0.6-1.2]$ & 65.2 & $0.5[-3.0-4.0]$ & 11.1 & $-1.2[-2.5-0.1]$ \\
\hline
\end{tabular}

The RRs and RCs [with CI] were adjusted for gender, age, BMI, smoking status, and comorbidity.

median TSH of subjects with known thyroid disease and TSH levels within normal range did not differ: $1.4 \mathrm{mIU} / \mathrm{L}$ (IQR 0.92.1). The median $\mathrm{FT}_{4}$ of euthyroid subjects without previously known thyroid disease was $13.3 \mathrm{pmol} / \mathrm{L}$ (IQR 12.1-14.6). The median $\mathrm{FT}_{4}$ of subjects with previously known thyroid disease and serum $\mathrm{TSH}$ and $\mathrm{FT}_{4}$ within the normal range was $14.3 \mathrm{pmol} / \mathrm{L}$ (IQR 12.5-15.9). This differed significantly from the $\mathrm{FT}_{4}$ levels of euthyroid subjects without previously known thyroid disease (RC 0.80 [CI 0.5-1.1]; $p<0.05$ after adjustment for possible confounders).

\section{Discussion}

In this cross-sectional population study, we found an association between the presence and severity of fatigue and low-normal serum TSH levels and high-normal $\mathrm{FT}_{4}$ levels. Although the magnitude of the differences was small and of dubious clinical significance, these results raise the question whether a serum TSH-value in the middle- or high-normal range would represent an optimal thyroid function. Indeed, the Rotterdam study has shown that a high-normal serum TSH level is associated with a lower risk of atrial fibrillation (16). However, other previous studies have shown a higher risk of cardiovascular mortality, an association with a higher blood pressure, a higher BMI, and a higher non-high-density lipoprotein cholesterol in subjects with serum TSH-values within the high-normal range $(12-15,17)$. These findings suggest that there may be different optimal serum TSH levels for each medical condition and symptom.

Previous studies have reported conflicting results regarding the association of thyroid function and fatigue in the general population. Canaris et al. reported more symptoms, including an increase of tiredness in subclinically and overtly hypothyroid subjects in comparison to euthyroid subjects in the Colorado study (2). The Colorado thyroid disease prevalence study was a large, cross-sectional population study that examined the prevalence of abnormal thyroid function by measuring the serum $\mathrm{TSH}$ and $\mathrm{FT}_{4}$ in 25,862 participants in a statewide health fair in Colorado in 1995. Besides the prevalence of thyroid dysfunction, the relationship between abnormal thyroid function and symptoms was examined, among which, the symptom of feeling more tired. Due to the larger study population, this study comprised more subclinically and overtly hypothyroid subjects in comparison to our study. Also, the symptom feeling more tired was evaluated as an increase of tiredness over time instead of tiredness as a current symptom. This may explain the discrepancy with our results with respect to

Table 5. Prevalence of Fatigue and Scores of the RAND-36 Vitality Subscale and SFQ by Medical History of Thyroid Disease

\begin{tabular}{|c|c|c|c|c|c|c|c|}
\hline \multirow[b]{2}{*}{ Subjects } & \multirow[b]{2}{*}{$\mathrm{n}$} & \multicolumn{2}{|c|}{ Self-reported fatigue } & \multicolumn{2}{|c|}{ RAND-36 vitality subscale } & \multicolumn{2}{|r|}{$S F Q$} \\
\hline & & $\%$ & $R R[C I]$ & Score & $\mathrm{RC}[\mathrm{CI}]$ & Score & $\mathrm{RC}[\mathrm{CI}]$ \\
\hline \multicolumn{8}{|l|}{ Total population } \\
\hline Without previously known thyroid disorder & 5897 & 34.4 & Reference & 66.2 & Reference & 11.2 & Reference \\
\hline With previously known thyroid disorder & 328 & 50.0 & $1.2[1.0-1.4]^{\mathrm{a}}$ & 61.8 & $-2.6[-4.5 \text { to }-0.6]^{\mathrm{a}}$ & 13.5 & $1.3[0.6-2.1]^{\mathrm{a}}$ \\
\hline \multicolumn{8}{|l|}{ Euthyroid subjects } \\
\hline Without previously known thyroid disorder & 5439 & 34.0 & Reference & 66.3 & Reference & 11.1 & Reference \\
\hline With previously known thyroid disorder & 221 & 52.3 & $1.3[1.0-1.5]^{\mathrm{a}}$ & 61.4 & $-2.9[-5.3 \text { to }-0.6]^{\mathrm{a}}$ & 13.7 & $1.4[0.5-2.3]^{\mathrm{a}}$ \\
\hline \multicolumn{8}{|l|}{ Subjects with thyroid dysfunction } \\
\hline Without previously known thyroid disorder & 458 & 39.6 & reference & 66.4 & Reference & 11.6 & Reference \\
\hline With previously known thyroid disorder & 107 & 45.1 & $1.1[0.8-1.5]$ & 62.6 & $-1.9[-5.8-1.9]$ & 13.2 & $1.4[-0.1-2.8]$ \\
\hline
\end{tabular}

The RRs and RCs [with CI] were adjusted for gender, age, BMI, smoking status, and comorbidity.

a $p<0.05$. 
the prevalence of fatigue in patients with overt or subclinical hypothyroidism. Another explanation is that the participants of our study were not aware of the fact that thyroid function was tested, and therefore this could not have affected their response to the questionnaire. Grabe et al. (11) found no increase in mental or physical complaints, including fatigue, in subjects with subclinical or overt hypo- or hyperthyroidism in a population study with 3790 participants of the Study of Health in Pomerania. Interestingly, subjects with overt or subclinical hyperthyroidism seemed to have less complaints in comparison to euthyroid subjects, but the prevalence of the symptom fatigue did not differ significantly (11). These results are in accordance with the results in our study. Neither of the previous studies examined the association between $\mathrm{TSH}_{\text {and }} \mathrm{FT}_{4}$ within the normal range and fatigue or used a validated test to establish the severity of fatigue.

In contrast with the association we found between the presence and severity of fatigue and low-normal TSH and high-normal $\mathrm{FT}_{4}$ levels, we could not detect an obvious association between overt or subclinical hypo- or hyperthyroidism and fatigue. This is also in contrast with the high prevalence of fatigue in patients with known thyroid dysfunction (5-7). One explanation may be that if thyroid dysfunction has led to complaints like tiredness, it is likely that these subjects have sought medical care and received therapy. These subjects were excluded from our analyses. This may have led to an underestimation of the association between thyroid dysfunction and fatigue in our study. Another explanation may be that thyroid dysfunction of the subjects in this study is less severe compared with the population consisting of referred patients. A third explanation might be that in our study, only a single blood sample was obtained for determining the thyroid hormone levels. Thyroid dysfunction can be transient and normalize spontaneously. These subjects might be less likely to complain of fatigue.

However, based on our data, we believe that this is not the only explanation for this discrepancy. The prevalence of fatigue in subjects with thyroid dysfunction in our study was $39.6 \%$, only slightly higher than the prevalence of fatigue in euthyroid patients, which was $34.0 \%$. Because of the high prevalence of both fatigue and thyroid (subclinical) dysfunction in the general population, it is likely that many patients who seek medical care because of fatigue, happen to be tired and by coincidence also have thyroid dysfunction, without any causal relationship. Patients with fatigue are more likely to have their thyroid status tested by the general practitioner and thyroid dysfunction will be found more often, despite the absence of a causal relationship. This kind of selection bias is called confounding by indication (28). Theoretically, treatment of thyroid dysfunction in these cases would not resolve the symptom fatigue. Although it is difficult to extend these findings of an epidemiological study to individual patients, we hypothesize that this might be the reason why in clinical practice, a subset of patients with thyroid dysfunction still complain of fatigue, despite optimal treatment and despite achieving euthyroidism. Our finding that subjects with known thyroid disease reported fatigue more often, had a lower RAND-36 vitality score and had a higher SFQ score, despite normal serum TSH and $\mathrm{FT}_{4}$ levels, supports this hypothesis. This hypothesis is also compatible with previous randomized controlled studies in which treatment of subclinical hypothyroidism and subclinical thyrotoxicosis had no effect on health-related quality of life and symptoms $(29,30)$.

Confounding by indication is one explanation for the finding that subjects with known thyroid disease reported fatigue more often, regardless of normal serum TSH and $\mathrm{FT}_{4}$ levels. Another explanation might be that the underlying disease, like chronic autoimmune thyroiditis, Graves' disease, or goiter, may cause fatigue regardless of the presence of thyroid dysfunction or is associated with other diseases, which may cause fatigue as well. Also, the fact that subjects are aware of having thyroid disease may influence their feeling of well-being and have an impact on their quality of life, which may result in a higher fatigue score. In addition, subtle abnormalities in the dynamics of thyroid hormone secretion, even within the normal range, should be considered; the $\mathrm{FT}_{4}$ levels of subjects with known thyroid disease and with thyroid hormone levels within the normal range were slightly higher in comparison to euthyroid subjects without known thyroid disease. Similar to our results, Engum et al. have reported an association between previously known thyroid disease and depression and anxiety, independent of thyroid function, in a large population-based survey (31).

We found no association between the level of TPOAbs and fatigue. This is in contrast with the recently described association between TPOAbs and both the presence of fatigue and the vitality subscale score of the SF-36 questionnaire (18). Perhaps, the difference in study population is the cause of this discrepancy. The study of Ott et al. (18) comprised euthyroid women with a benign goiter. Our study was population based, comprising both men and women, without known thyroid disease.

Our study has some limitations. Because of the crosssectional observational nature of our study, no causal relationship or lack of causal relationship can be determined. Second, the results in the group of patients with overt hypothyroidism or thyrotoxicosis should be interpreted cautiously, as only a small number of participants were found to have an overt thyroid dysfunction. We did not measure triiodothyronine $\left(T_{3}\right)$, so we might have missed some cases of overt thyrotoxicosis in subjects with normal $\mathrm{FT}_{4}$ and elevated $\mathrm{T}_{3}$ and misclassified those subjects as having a subclinical thyrotoxicosis. Third, antibodies against thyroglobulin were not measured in this epidemiological survey, so we might have missed some cases of autoimmune thyroiditis (32). Fourth, despite the fact that the subscale vitality of the RAND-36 and the SFQ we used have been validated as excellent tools to screen for the presence and severity of fatigue, these instruments have only a limited value with respect to their ability to differentiate and quantify all the dimensions of fatigue. It is difficult to establish the clinical meaningfulness of a 1-point higher score on a fatigue scale. Finally, we cannot rule out a selection bias due to a difference in fatigue or thyroid function in the responders group versus the nonresponders group and we cannot rule out the presence of other, unmeasured possible confounders.

In conclusion, within the normal range of $\mathrm{TSH}$ and $\mathrm{FT}_{4}$, fatigue seemed more severe in subjects with low-normal TSH levels and high-normal $\mathrm{FT}_{4}$ levels than middle-normal TSH and $\mathrm{FT}_{4}$ levels, although the effect was small. Subjects with a history of thyroid disease, but with normal TSH and $\mathrm{FT}_{4}$ 
concentrations, experience more fatigue than the general population. The reasons for this are unclear, but subtle abnormalities in the dynamics of thyroid hormone secretion should be considered.

\section{Disclosure Statement}

The authors declare that no competing financial interests exist.

\section{References}

1. Bjøro T, Holmen J, Krüger $\varnothing$, Midthjell $K$, Hunstad $K$, Schreiner T, Sandnes L, Brochmann H 2000 Prevalence of thyroid disease, thyroid dysfunction and thyroid peroxidase antibodies in a large, unselected population. The Health Study of Nord-Trøndelag (HUNT). Eur J Endocrinol 143:639-647.

2. Canaris GJ, Manowitz NR, Mayor G, Ridgway EC 2000 The Colorado thyroid disease prevalence study. Arch Intern Med 160:526-534.

3. Hollowell JG, Staehling NW, Flanders WD, Hannon WH, Gunter EW, Spencer CA, Braverman LE 2002 Serum TSH, $\mathrm{T}_{4}$, and thyroid antibodies in the United States population (1988 to 1994): National Health and Nutrition Examination Survey (NHANES III). J Clin Endocrinol Metab 87: 489-499.

4. Hoogendoorn EH, Hermus AR, de Vegt F, Ross HA, Verbeek AL, Kiemeney LA, Swinkels DW, Sweep FC, den Heijer M 2006 Thyroid function and prevalence of anti-thyroperoxidase antibodies in a population with borderline sufficient iodine intake: influences of age and sex. Clin Chem 52:104-111.

5. Canaris GJ, Steiner JF, Ridgway EC 1997 Do traditional symptoms of hypothyroidism correlate with biochemical disease? J Gen Intern Med 12:544-550.

6. Lazarus JH 1997 Hyperthyroidism. Lancet 349:339-343.

7. Lindsay RS, Toft AD 1997 Hypothyroidism. Lancet 349:413417.

8. Jameson JL, Weetman AP 2010 Disorders of the thyroid gland. In: Fauci AS, Braunwald E, Kasper DL, Hauser SL, Longo DL, Jameson JL, Loscalzo J (eds) Harrison's Principles of Internal Medicine, 17th edition. Available online at www.accessmedicine.com/content.aspx?aID $=2877285$

9. Jaeschke R, Guyatt G, Cook D, Harper S, Gerstein HC 1994 Spectrum of quality of life impairment in hypothyroidism. Qual Life Res 3:323-327.

10. Watt T, Hegedüs L, Rasmussen AK, Groenvold M, Bonnema SJ, Bjorner JB, Feldt-Rasmussen U 2007 Which domains of thyroid-related quality of life are most relevant? Patients and clinicians provide complementary perspectives. Thyroid 17:647-654.

11. Grabe HJ, Völzke H, Lüdemann J, Wolff B, Schwahn C, John U, Meng W, Freyberger HJ 2005 Mental and physical complaints in thyroid disorders in the general population. Acta Psychiatr Scand 112:286-293.

12. Asvold BO, Vatten LJ, Nilsen TI, Bjøro T 2007 The association between TSH within the reference range and serum lipid concentrations in a population-based study. The HUNT Study. Eur J Endocrinol 156:181-186.

13. Asvold BO, Bjøro T, Nilsen TI, Vatten LJ 2007 Association between blood pressure and serum thyroid-stimulating hormone concentration within the reference range: a population-based study. J Clin Endocrinol Metab 92:841845.
14. Asvold BO, Bjøro T, Nilsen TI, Gunnel D, Vatten LJ 2008 Thyrotropin levels and risk of fatal coronary heart disease. The HUNT study. Arch Intern Med 168:855-860.

15. Fox CS, Pencina MJ, D'Agostino RB, Murabito JM, Seely EW, Pearce EN, Vasan RS 2008 Relations of thyroid function to body weight: cross-sectional and longitudinal observations in a community-based sample. Arch Intern Med 168:587592.

16. Heeringa J, Hoogendoorn EH, van der Deure WM, Hofman A, Peeters RP, Hop WC, den Heijer M, Visser TJ, Witteman JC 2008 High-normal thyroid function and risk of atrial fibrillation: the Rotterdam study. Arch Intern Med 168:22192224.

17. Roos A, Bakker SJ, Links TP, Gans RO, Wolffenbuttel BH 2007 Thyroid function is associated with components of the metabolic syndrome in euthyroid subjects. J Clin Endocrinol Metab 92:491-496.

18. Ott J, Promberger R, Kober F, Neuhold N, Tea M, Huber JC, Hermann M 2011 Hashimoto's thyroiditis affects symptom load and quality of life unrelated to hypothyroidism: a prospective case-control study in women undergoing thyroidectomy for benign goiter. Thyroid 21:161-167.

19. Hays RD, Sherbourne CD, Mazel RM 1993 The RAND 36Item Health Survey 1.0. Health Econ 2:217-227.

20. Ware JE Jr, Sherbourne CD 1992 The MOS 36-item shortform health survey (SF-36). I. Conceptual framework and item selection. Med Care 30:473-483.

21. Aaronson NK, Muller M, Cohen PD, Essink-Bot ML, Fekkes M, Sanderman R, Sprangers MA, te Velde A, Verrips E 1998 Translation, validation, and norming of the Dutch language version of the SF-36 Health Survey in community and chronic disease populations. J Clin Epidemiol 51:1055-1068.

22. VanderZee KI, Sanderman R, Heyink J 1996 A comparison of two multidimensional measures of health status: the Nottingham Health Profile and the RAND 36-Item Health Survey 1.0. Qual Life Res 5:165-174.

23. Alberts M, Smets EM, Vercoulen JH, Garssen B, Bleijenberg G 1997 'Abbreviated fatigue questionnaire': a practical tool in the classification of fatigue. Ned Tijdschr Geneeskd 141:1526-1530.

24. Alberts M, Vercoulen JHMM, Bleijenberg G 2001 Assessment of fatigue-the practical utility of the subjective feeling of fatigue in research and clinical practice. In: Vingerhoets (ed) A Assessment in Behavioral Medicine, first edition, Brunner-Routledge, London, pp 301-327.

25. Callas PW, Pastides H, Hosmer DW 1998 Empirical comparisons of proportional hazards, poisson, and logistic regression modeling of occupational cohort data. Am J Ind Med 33:33-47.

26. Mittlbock M, Heinzl H 2001 A note on R2 measures for poisson and logistic regression models when both models are applicable. J Clin Epidemiol 54:99-103.

27. Zou G 2004 A modified poisson regression approach to prospective studies with binary data. Am J Epidemiol 159:702-706.

28. Knottnerus JA, Knipschild PG, Sturmans F 1989 Symptoms and selection bias: the influence of selection towards specialist care on the relationship between symptoms and diagnosis. Theor Med 10:67-81.

29. Surks MI, Ortiz E, Daniels GH, Sawin CT, Col NF, Cobin RH, Franklyn JA, Hershman JM, Burman KD, Denke MA, Gorman C, Cooper RS, Weissman NJ 2004 Subclinical thyroid disease: scientific review and guidelines for diagnosis and management. JAMA 291:228-238. 
30. Villar HC, Saconato H, Valente O, Atallah AN 2007 Thyroid hormone replacement for subclinical hypothyroidism. Cochrane Database Syst Rev 18:CD003419.

31. Engum A, Bjoro T, Mykletun A, Dahl AA 2002 An association between depression, anxiety and thyroid function-a clinical fact or an artefact? Acta Psychiatr Scand 106:27-34.

32. McLachlan SM, Rapoport B 2004 Why measure thyroglobulin autoantibodies rather than thyroid peroxidase autoantibodies? Thyroid 14:510-520.
Address correspondence to: Annenienke C. van de Ven, M.D. Department of Endocrinology (471) Radboud University Nijmegen Medical Centre Geert Grooteplein 8

P.O. Box 9101 6500 HB Nijmegen The Netherlands

E-mail: ac.ven@aig.umcn.nl 